\title{
"We all need employment" - An exploration of the factors which influence the return-to-work after a severe traumatic brain injury
}

\author{
Claire-Lynn Moller, BSc OT (WITS), MOT (UKZN) \\ Independent Practitioner in Medico-legal and Vocational Rehabilitation
}

Thanalutchmy Lingah, BOct (UDW), MBA (Wales)

Lecturer and Clinical Supervisor, Discipline of Occupational Therapy, School of Health Sciences, University of Kwa-Zulu Natal

Standford Mandla Phehlukwayo, Dip OT (MEDUNSA), LLM (Public Health) (UKZN), B Occ Ther (Hons) (MEDUNSA), Ergonomics Risk Auditors certificate (Ergomax Pty Ltd)

Lecturer and Clinical Supervisor, Discipline of Occupational Therapy, School of Health Sciences, University of Kwa-Zulu Natal.

Introduction: While individuals with mild and moderate traumatic brain injury (TBI) manage to achieve some degree of successful return-to-work, individuals with severe TBI have a reduced chance of returning to work. This study aimed at investigating how personal factors, workplace environment and vocational rehabilitation influenced the return-to-work and assumption of the worker role of individuals with severe TBI.

Method: A phenomenographic study design with purposive sampling was used to select I I participants. Data were collected through semi-structured interviews using the Worker Role Interview as a guide. Data were thematically analysed using Clarke and Braun's six phases of thematic analysis.

Results: Two themes emerged: It's all about me, which addressed the internal aspects of the role of a worker and The support for me which focused the external factors of personal, work and rehabilitative support.

Conclusion: Results showed that rehabilitation, personal factors and work support were critical for successful return-to-work for survivors of severe TBI. Results indicated that participation in work was as important in developing self-worth as participation in any other area of daily living. With regard to personal factors, rehabilitation and support were vital in maintaining self-worth after an injury. This could be enhanced through vocational rehabilitation.

Key words: Traumatic brain injury, return-to-work, vocational rehabilitation

\section{INTRODUCTION}

Traumatic brain injury (TBI) often results in residual cognitive, behavioural, physical and functional impairments that may influence the person's independence in most areas of occupation, including work. TBI is classified into mild, moderate and severe injury using the I5-point Glasgow Coma Scale (GCS)' of which the degree of impairment depends on the severity of injury sustained. The objectives of the study were to investigate how personal factors, workplace environment and vocational rehabilitation influenced the return-to-work and the assumption of the worker role of individuals with severe TBl's who had a successful pre-injury employment.

Most individuals who have sustained a TBI are of working age and fulfil the role of a worker yet return-to-work is not a term that is commonly associated with this population group ${ }^{2}$. Furthermore, limited attention has been paid to vocational rehabilitation and return-to-work of survivors of severe TBI's. Conklin, Flaumer and Venables ${ }^{3}$ regarded vocational rehabilitation as a predictor for return-to-work and sustained employment. Gilworth et al ${ }^{4}$ further assert that vocational rehabilitation significantly impacts on the return-to-work process. While individuals with mild and moderate TBI's manage to achieve some degree of successful return-to-work, individuals with severe TBl's experience large scale marginalisation ${ }^{4}$.

Engagement in the worker role is a complex phenomenon which involves dynamic interaction between internal factors such as motivation and external factors such as societal perceptions of people with disabilities. With severe TBI, these internal and external factors are compounded by the severity of the injury, which negatively affects the ability of those suffering from a severe TBI from participating in the worker role. Access to rehabilitation services can assist with remediation of residual impairments and facilitate alternative methods of engaging in the occupation of work.

It is acknowledged that individuals with severe TBI can, to some degree, return-to-work ${ }^{2,5-8}$ however there is a gap in existing knowledge about individuals with a severe TBI returning to work after having had stable, secure and skilled pre-injury employment. Considering this, there is a need to understand factors which influence the return-to-work for individuals with severe TBl's in South Africa. This will contribute towards the development of a client-centred vocational rehabilitation programme for severe TBI individuals in addressing the underlying cause of the low employment rate of people with disabilities.

\section{LITERATURE REVIEW}

According to the World Health Organisation, TBl's are reportedly the leading cause of both death and disability with the assumption that the more severe the injury, the more significant the disability 9 Globally, more than $5 \%$ of people suffer from a serious brain injury ${ }^{10}$. Population- based studies show that the incidence of $T B I$ is between 91 per 100000 in Spain, I 80 and 250 per 100000 per year in the United States, 322 per 100000 in the South of Australia and 316 per 100000 in South Africa ". This indicates a high incidence in South Africa when compared to other countries.

There is an estimated 89,000 new cases of TBl's reported an- 

Inclusion Criteria
* Diagnosed on admission to a medical facility or by a neurologist/ neurosurgeon as having sustained a severe TBI (GCS score of between 1-8).
* A minimum of 3-5 years post injury.
* A minimum of 3 years of premorbid stable skilled employment.
* Male or female individuals between the working ages of 23 years -65 years at the time of the accident.
* Male or female individuals who are or are not currently employed in the open labour market.
* Male or female individuals whom, with or without the use of a translator, can understand and respond to verbal questions.

nually in South Africa ${ }^{10}$. According to Statistics South Africa ${ }^{12}$, the total deaths from "other external causes of accidental injuries"12:44 contributed to $60 \%$ of non-natural deaths in 2014. Between January 2014 and January 2016, a provincial hospital in the Eastern Cape had a 90 in 100000 incidence of TBI. Of those TBl's, $73.7 \%$ were in working aged individuals ${ }^{13}$. In KwaZulu-Natal, data analysed from a tertiary hospital between January 2009 and December 2013 found that isolated, severe brain injuries accounted for 24 in $100000^{14}$. The prevalence and severity of TBI at a national level in South Africa is currently unknown.

Considering that most of these individuals are of working age and fulfil the worker role, time off work or the inability to return-to-work could have a substantial impact on the economy. Despite comprehensive labour legislation and policies protecting and promoting the employment of people with disabilities in South Africa, the inclusion of people with disabilities into the open labour market is poor ${ }^{15}$. Identification of the factors influencing the return-to-work of severe TBl's will contribute towards addressing the underlying cause of poor return-to-work of people with disabilities.

Internationally, individuals having sustained a severe TBI have up to a $74 \%$ lower chance of return-to-work than mild and moderate injuries $^{16}$. The more severe the TBI, the worse the employment outcomes ${ }^{17}$, with a lower probability of maintaining the employment $^{18}$. In South Africa, individuals having sustained a TBI had a $32 \%$ return to competitive employment ${ }^{19}$ however there was no indication in the study regarding the severity of the injury. Considering the return-to-work success rate of severe TBI's, it can be assumed that the most affected category in this regard were severe TBI's.

Following a severe TBI, impairments in cognitive, behavioural, physical and functional skills are considered immense and complex. Grauwmeijer et $\mathrm{al}^{20}$ noted that the complex consequences of a

\section{Exclusion Criteria}

* Individuals who may have additional premorbid or current psychiatric diagnosis according to the DSM V.

* Individuals who make use of wheelchairs as their main form of mobility.

* Individuals who are required to use prosthetic limbs to facilitate function.

severe TBI was a limitation for return-to-work. Reduced selfawareness as well as emotional and behavioural dyscontrol are also considered complex consequences of severe TBI which, in turn, impede return-to-work ${ }^{21-23}$.

Rehabilitation focuses on restoring function in basic and instrumental activities of daily living where vocational rehabilitation is directed towards restoring function related to a work environment ${ }^{24}$. Vocational rehabilitation significantly impacts on the return-to-work process and should therefore be considered part of the primary rehabilitation goal ${ }^{4}$.

In South Africa, the National Rehabilitation Policy ${ }^{25}$ was developed to provide therapeutic and client-centred rehabilitation to individuals at a Primary Health Care level; but there seems to be some implementation challenges to this policy. Current research shows that vocational rehabilitation is isolated, limited and fragmented in both rural and urban areas of South Africa ${ }^{26,27}$.

\section{METHOD}

\section{Study design}

In this study, the aim was to explore how severe TBI influences the performance of the worker role and the return-to-work process following injury. A phenomenographic study design was used to meet this aim. This research design was selected because it allows the researcher to explore the real-life situations and individual perspectives and variations regarding factors influencing their situation ${ }^{28,29}$

\section{Population and sampling}

To enhance variation in the research, purposive sampling was used to select eleven participants for this study based on a theoretical saturation sample size ${ }^{29}$ and predetermined inclusion and exclusion criteria. See Table I.

Table II: Participant Profile

\begin{tabular}{|c|c|c|c|c|c|c|c|c|}
\hline $\begin{array}{l}\text { Participant } \\
\text { Code }\end{array}$ & Gender & Race & $\begin{array}{l}\text { Severity of } \\
\text { Injury on } \\
\text { admission }\end{array}$ & $\begin{array}{l}\text { Age at } \\
\text { Time of } \\
\text { Injury }\end{array}$ & $\begin{array}{c}\text { Years Since } \\
\text { Injury }\end{array}$ & $\begin{array}{c}\text { Period on } \\
\text { Previous Job }\end{array}$ & Rehabilitation & Province \\
\hline $\mathrm{FI}$ & $\mathrm{F}$ & W & $3 / 15$ & 25 & 10 & 5 & In-patient & Gauteng \\
\hline $\mathrm{F} 2$ & $\mathrm{~F}$ & W & $6 / 15$ & 45 & 13 & 15 & Out-patient & KwaZulu-Natal \\
\hline MI & M & $\mathrm{B}$ & $5 / 15$ & 27 & 3 & 3 & None & Free State \\
\hline M2 & M & B & $7 / 15$ & 29 & 8 & 10 & None & Gauteng \\
\hline M3 & M & B & "Severe Diffuse" & 54 & 3 & 20 & None & Limpopo \\
\hline M4 & $M$ & W & $5 / 15$ & 35 & 5 & 5 & None & Gauteng \\
\hline M5 & $M$ & W & $3 / 15$ & 60 & 8 & 35 & Out-patient & KwaZulu-Natal \\
\hline M6 & M & 1 & $6 / 15$ & 22 & 3 & 3 & Out-patient & KwaZulu-Natal \\
\hline M7 & $M$ & B & $8 / 15$ & 33 & 5 & 10 & None & KwaZulu-Natal \\
\hline M8 & M & 1 & $1 / 15$ & 29 & 12 & 3 & In-patient & KwaZulu-Natal \\
\hline M9 & $M$ & B & $7 / 15$ & 44 & 16 & 13 & None & Eastern Cape \\
\hline
\end{tabular}

Codes: W - white, B - black, I - Indian, F - female, M - male, GCS - Glasgow Coma Scale 
Table III: Thematic Analysis of data

\begin{tabular}{|c|c|}
\hline Clarke \& Braun's Thematic Analysis & Description of the thematic analysis procedure followed \\
\hline Familiarisation with the data & $\begin{array}{l}\text { This was established by listening to the audiotaped data and reading the transcripts several } \\
\text { times. } \\
\text { By reading the data semantically, interesting features were identified that were relevant to the } \\
\text { research question. These were highlighted and recorded separately. }\end{array}$ \\
\hline Coding & $\begin{array}{l}\text { The highlighted data were systematically coded to address each of the research objectives. } \\
\text { Using an inductive approach, each code summarised the meaning of the data (Sematic codes }{ }^{31} \text { ). } \\
\text { Eachal list of codes was compiled using a table format in Microsoft Word } 2010 \text {. } \\
\text { Eata was collated to the respective codes. }\end{array}$ \\
\hline Searching for themes & $\begin{array}{l}\text { Considering the research aim, similarities were identified from each code. } \\
\text { To develop the themes, a broader pattern of meaning was identified from each coded data. } \\
\text { A more detailed code became the main focus of a theme. } \\
\text { and concise for answering the research aim while similar codes were collapsed. }\end{array}$ \\
\hline Reviewing potential themes & $\begin{array}{l}\text { Four original themes were established. } \\
\text { Each theme was reviewed further and developed in accordance to the research aim. } \\
\text { By discarding one theme and integrating two themes into each other, two major themes were } \\
\text { finalised that answered the research aim. } \\
\text { Each theme had a series of sub-themes and categories. } \\
\text { Using a thematic map, the relationship between each theme and sub-theme was established } \\
\text { and described an analytic story }{ }^{3 !} \text {. }\end{array}$ \\
\hline Defining and naming themes & $\begin{array}{l}\text { A detailed definition described the complexity of the data that was given to each theme. } \\
\text { Specific extracts that best described the essence and meaning of each theme, sub-theme and } \\
\text { category were sourced from the collated data. } \\
\text { Each theme was then named based on the overall essence of the data. }\end{array}$ \\
\hline Producing the report & $\begin{array}{l}\text { Each named theme was further reviewed to determine a particular order so as to better } \\
\text { express the analytical story }{ }^{3 !} \text {. } \\
\text { The data were then written up to tell the reader a comprehensible story about the collected } \\
\text { data in relation to the research objectives and research question. }\end{array}$ \\
\hline
\end{tabular}

Variation was facilitated as the study sample comprised two females and nine males of difference race groups and resided in six different provinces within South Africa. Injury periods ranged from 3 - 16 years and a stable premorbid employment period ranged from $3-35$ years. Types of employments varied from unskilled, semi-skilled and skilled work types. See Table II on pagel 8.

\section{Data collection procedures and management}

Data were collected between 0 I July 2016 and 3I September 2016 using audio-taped semi-structured interviews. Questions were guided by The Worker Role Interview (WRI) questionnaire. The WRI is a work-related assessment tool developed by Kielhofner ${ }^{30}$ and assesses volition, habituation and performance in relation to the environment and to work. Four interviews were conducted in a private office at a medico-legal practice. Four interviews were conducted at the home of the participant and three interviews were conducted at a common meeting place where privacy was ensured. Each participant was provided with a number to ensure confidentiality and anonymity. Biographical data, prior and current employment and their initial GCS reading were obtained. Data were collected using audiotapes, field notes, observations of non-verbal behaviour and reflective journaling. This established credibility in the study. Following completion of the interview, the audiotapes were transcribed precisely as spoken and re-read for accuracy and consistency before data analysis commenced. The audiotapes were saved onto an external hard drive and locked in a safe.

\section{Data analysis}

Using a second-order perspective ${ }^{31}$ to analyse the variation of participants' experiences of the factors influencing their returnto-work, the Clarke and Braun's ${ }^{32}$ six phases of thematic analysis was utilised. Data were inductively organised into codes, themes, sub-themes and categories of description before being written up. Verbatim quotes were then used to describe the meaning of the data gathered. This is described further in Table III.

\section{Trustworthiness}

Credibility, validity, dependability and confirmability were ensured/ established to achieve trustworthiness in this study. To establish credibility, exact quotations were used to demonstrate the relationship between the data and categories of description. Peer debriefing allowed for categories of description to be further analysed and any queries answered. Prolonged engagement in the research over one year was used to ensure credibility ${ }^{33}$. The results of this study were related to similar studies ${ }^{4-8}$ to determine the validity of the findings. Dependability and confirmability were achieved by utilising an audit trail, code-recode and reflexive journal strategies during data collection and analysis ${ }^{4}$.

\section{Ethical considerations}

This research study was approved by the Biomedical Research Ethics Committee (BREC) at the University of Kwa-Zulu Natal (Ref. no BE $21 \mathrm{I} / 16$ ) on the 08 June 2016. To ensure scientific integrity, the research process was carried out according to the research guidelines. Gatekeeper's permission was obtained from medico-legal practices and participation in the research study was voluntary. Informed consent was obtained from each participant and those who travelled a distance were reimbursed in full for travel expenses incurred.

\section{RESULTS}

Two main themes emerged from this study namely; It's all about me and The support for me. The first theme, It's all about me had three sub-themes with corresponding categories of descriptions which included my role as a worker, my abilities in the role and my emotions in the role. The second theme, The support for me comprised of three sub-themes with corresponding categories of descriptions namely; personal support, work support and rehabilitative support experienced by the participants. After all categories of descriptions had been considered, the outcome space resulted in the understanding of how return-to-work aids in the development of self-worth. Figure $I$ on page 20 is a diagrammatic representation of the key themes, sub-themes and subsequent categories of description: 


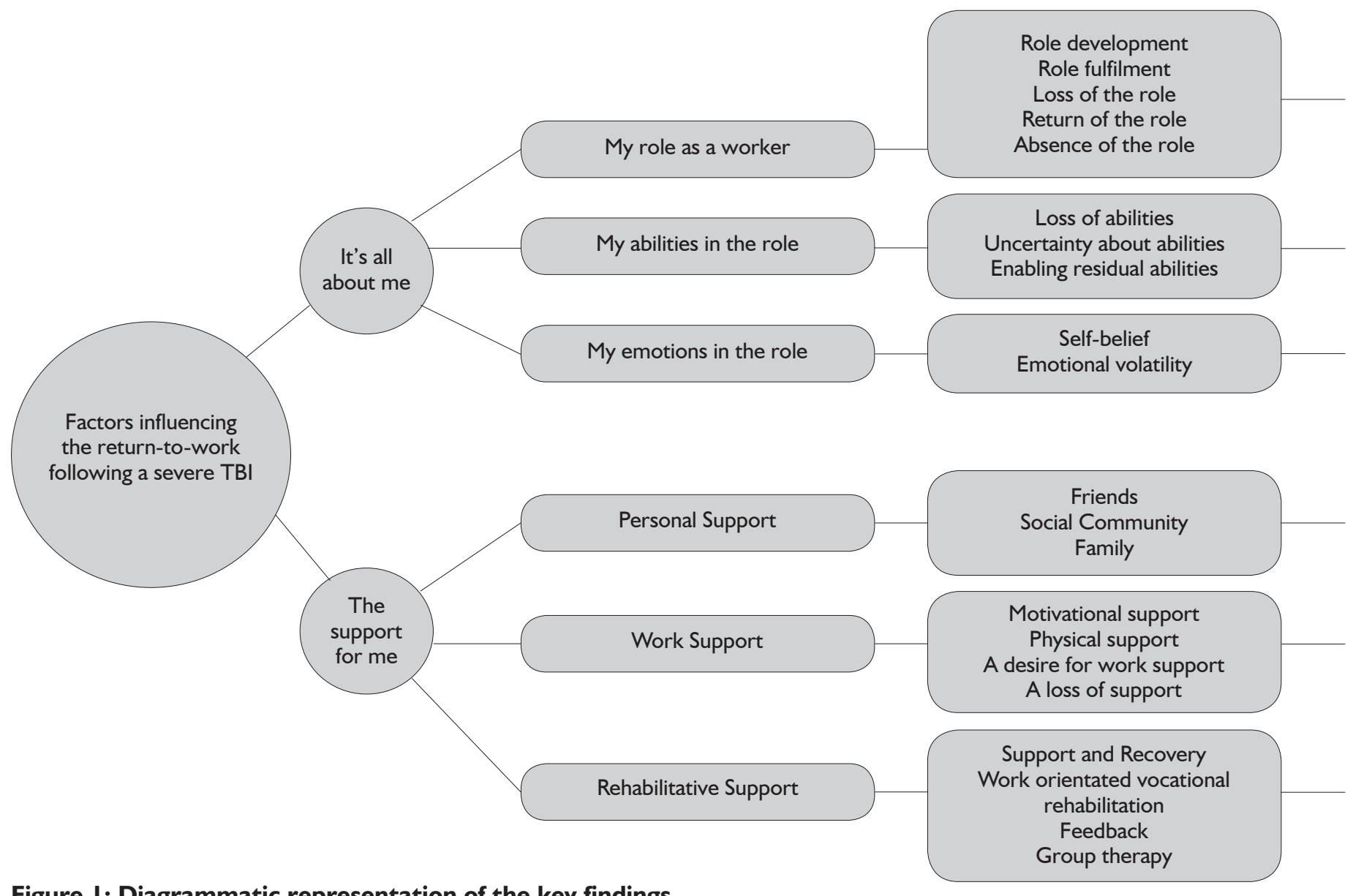

Figure I: Diagrammatic representation of the key findings

\section{Theme I: It's all about me}

\section{My role as a worker}

This sub-theme describes categories of role development, role fulfilment, the loss of the worker-role, the return of the role and the absence of the role.

Role development is established from experience, interests that guide choices and personality which reflects commitment, attraction and investment in the worker role. In response to role development, one participant felt that the fulfilment of the worker role was based on interest and knowledge that he had grown up with.

I've liked it and I have know[n] it. I've learnt it. My father ha[s] learn[t] it before... that's a job I would like to do almost. [M2]

On the other hand, another participant added that her role was developed through experience.

oh well, I've been teaching, for... so many years... I5 years... so I know...what is expected, from, the $4-5$ year old... it's like the back of my hands. [FI]

Role fulfilment describes the intrinsic needs to serve and contribute to the greater community, develop and transfer skills and grow professionally. One participant perceived role fulfilment as more than just doing what was required, but also as making an impact.

I couldn't come and just sit there, and do daily work and leave, I have to make a difference. [M5]

Three participants concurred that work was important to allow for the worker role to be transferred and developed, therefore allowing for personal growth.

When I was working, I still learn new things which in future, even if I'm at... at... I'm not at the firm, I can still do it at [sic] the township. [M3]
Furthermore, professional growth was important in role fulfilment.

I must learn from the one who knows everything about machine[s] so that if tomorrow I'm going alone there, I know what I am going to do. [M2]

The loss of the role was identified as a loss of opportunities and a sense of isolation. Seven participants spoke of lost opportunities.

It was a reduced role... It was like work basically put me in this corner and forgot about me you know, give [giving] me something that is not going to really affect the company as a whole. I did the bare minimum just to fill my day so that's what they wanted me to do. [M8]

Four participants were unemployed and noted that the loss of the worker role resulted in a sense of isolation due to an inconsistent routine, poor use of time and reduced social participation.

I hardly socialize. I hardly go out... I don't do anything. I just stay at home and watch TV. That's what I do. That's it. [M7]

The return of the role was better facilitated when some form of vocational rehabilitation was received.

Slowly get back into work...start working five days half days and over a 3-week period they would ... they would monitor and see how I cope and then after that they would increase the days. [M5]

The absence of the role was noted in nine participants who did not receive vocational rehabilitation. They were unaware that this type of rehabilitation existed.

If I had even been aware that there was such a thing it would have been much easier. [M4]

My abilities in the role

This sub-theme comprises three categories namely the loss of abilities, uncertainty of residual abilities and environmental influences and enabling residual abilities. 
The loss of abilities addresses the physical and cognitive abilities lost and the loss of performance skills. The physical loss included, but was not limited to pain, balance fall-outs, reduced pace, presence of post-traumatic epilepsy, residual fractures and headaches.

I can't sit in one place. I can't stand for long. I can't lie down for too long in the bed. So it's like something to do with my body. That's why. I can't be like in one position for all the time... I feel uncomfortable in whatever position. [M6]

A loss in cognitive abilities included, but was not limited to fallouts in orientation, understanding, decision making, planning, problem solving, memory and processing.

It was one of the most difficult things I ever had to do, just I couldn't think, I couldn't think at all... everything was very, very difficult... just hard to think and slow at the time [reduced processing of information]. [F2]

The loss of performance skills were identified as a loss in specific abilities obtained in the job.

Previously I was good with computers but nowadays I am battling a little bit with it. [M4]

I wanted to go and work but I couldn't drive. [M5]

Uncertainty about residual abilities and environmental influences was apparent in participants who were unemployed or who were employed in sheltered employment. Due to the loss of a worker role, uncertainty regarding future employment in the open labour market was related to the fact that they just 'did not know'.

I don't know, maybe all, I need to try and find out if I can still do it, maybe I can still do all of this but in [at] a slow rate [I] can still do most of it but slower, in the [sic] more time maybe [I can] do it. [M7]

When asked whether participants believed they would manage in a changed environment, a sense of uncertainty emerged.

One where they stand, there is no, there is no dust, [or] noise . I will just sleep. Where there's the dust, there's a noise, they... will ... my body they will ... influence my body. [M2]

Enabling residual abilities was facilitated through compensation. Confidence was therefore gained so as to continue to fulfil the worker role.

So I have said 'how can I overcome this that I don't forget something I have asked her to do and then she still has not done it?' Now I have a book and every e-mail that I send to her I stick in the book and as it comes back to me I tick it off. [F2]

To further enable residual abilities, work-specific vocational rehabilitation was thought to enable residual abilities.

$\operatorname{Dr}$ [name] also came to my work, she met my bosses, she met the doctors, she took a walk to see where I fell and she was exposed to what it was so she knew how to set up her rehab... she was also able to programme the rehab around what work wanted. [M8]

\section{My emotions in the role}

This sub-theme describes categories of self-belief (including selfesteem, acceptance, confidence and self-image) and emotional volatility.

Self-belief describes how participation in the worker role develops self-esteem despite the fact that the impact of the injury results in a disbelief-in-self. Regarding self-esteem, all participants described a sense of confidence, happiness, independence, pride, fulfilment, reward and recognition.

There [are] still some times when... when I go to the shops. There was one lady that I trained. She still remembers me by name. I can't remember her name but she still remembers me by name and she will come to me and say, she will tell a friend or something like that and will say 'that's the guy that took me for my driver's licence'. So know- ing that you took that person and helped that person to get a driver's licence. That was, that was actually nice. [M4]

Development of confidence was portrayed by enabling residual abilities. Recovery to whatever degree allowed for a level of acceptance and enhanced confidence.

I've come to terms with it now and accepted where I am and what happened, and because I'm ok with myself now...I ... I'm not worried about people that don't accept me...so I think, I'm not afraid of putting myself out. [FI]

Disbelief-in-self emerged as a great imposition in return-towork and reduced the confidence experienced.

I don't want to draw attention... just now the suggestion I make is not right and they think 'ja that guy is stupid or something...' Maybe because they will think I'm stupid... I am just scared that maybe I won't be able to do the work. [M4]

When it was explored whether VR would be useful, the general consensus was that it would be. However a reduced belief-in-self raised concerns regarding how this intervention would be perceived by others.

If they know about it, what if they, like feel sorry for you...they will treat you differently from now...shame, poor guy, go sit there in the corner. [M4]

A reduced self-confidence was exacerbated by a reduced selfimage as a result of the physical injuries sustained.

Because of my appearance now, I was scared about what people think because of my eye. My face was disigured badly. It is still a bit like that. [M6]

Emotional volatility describes emotions of depression and anger experienced by all participants.

When I don't keep myself busy and I have too much time to think and do nothing, I get depressed and so, I enjoy the work. [M3]

In a working environment, two participants noted the challenge of anger management.

It has been very hard to control my temper and to control what I say. [M8]

\section{Theme II: The support for me}

\section{Personal support}

Personal support was described as support from friends, a social community and family that influenced the return-to-work.

I'm living with people who you ...cannot regard me as an outcast. Who still value me. So therefore in that regard, I think it's playing a very important role. It moulds me into accepting that you see I still have value to offer to people. [M3]

As a consequence of not returning to work, a loss of personal support was experienced by seven participants.

I'm usually at home so I hardly got [have] any friends now. [M7]

\section{Work support}

Support from colleagues and employers emerged as an instrumental facilitator in the return-to-work. Categories arising from this subtheme included motivational support, physical support, desire for support and loss of support.

Motivational support was best described by a participant placing egocentric value to such support.

His colleagues and employer... telling the learners you see, this man who played a very important role. So such... such type of instances made me feel very confident in my execution of duties instead of loathing the profession. In my view I should have left the profession long ago. [M3]

Physical support was noted when participants were compensated or accommodated for their reduced physical ability. 
I talk to [colleague's name], [colleague's name] I want to have a little rest now and [colleague's name] would say just 'go... when the makhulu boss [senior boss] come [sic] I tell him you are in the bathroom'. [M2]

A desire for work support was experienced by nine participants who did not receive vocational rehabilitation intervention. One participant felt that the benefits of vocational rehabilitation could have facilitated support and understanding.

If there will be someone to tell him... he's willing to work. He can do the job but the problem is this and this. [M2]

The loss of support was seen as a direct barrier to return-towork following a severe TBI.

When I got back to work, all my stuff had been packed up into a box and they had already planned ... and he had actually already made arrangements to move me to a department, a clinic downstairs in the dungeon, miles away from where I was. [F2]

The loss of support was noted by five participants as a loss of social interaction with colleagues.

It's very, very difficult to have ... to make friends with colleagues because they see it a preferential treatment. [FI]

\section{Rehabilitative support}

Only two participants received some degree of vocational rehabilitation and subsequent rehabilitative support. Categories derived from this sub-theme included support and recovery, work orientated vocational rehabilitation, feedback between employer and Vocational Rehabilitation specialist and group therapy.

Support and recovery was influential in facilitating returnto-work.

I would have never been able to have an exponential recovery, I still say exponential, because the dedication of the rehab team was out of this world. [M8]

Work orientated vocational rehabilitation facilitated the professional growth of the participants.

Because of what I learnt in rehab and how I have compensated has bought me four years into this company. [M8]

Feedback between the employer and Vocational Rehabilitation specialists resulted in subsequent support for the participants.

I think they [employer] were very good to me ... they just went along, I was seeing [neuropsychologist] every week um ... she gave them some feedback as well, um ja ... I don't think... I know there was not any pressure or anything in terms of not going back to work. [M5]

Group therapy as part of the vocational rehabilitation process facilitated rehabilitative support.

$\operatorname{Dr}$ [name], she used to have sessions with similar injury people, she used to have round table and discuss issues and talk about to each other and each try to help the other and help to fix it and she would also come in and input ways of how to fix problems and how to handle the anger...I have learnt a lot on how to control and work with the anger side of things, which has helped my job. [M8]

\section{DISCUSSION}

The aim of this study was to investigate how personal attributes, developed habits and routines, residual performance skills and environmental factors influenced the return-to-work of severe TBI's who had a stable and secure pre-injury employment.

The first theme, "it's all about me" was about the worker role being an integral part of one's existence that provided a sense of self-worth. These findings are supported by literature from Greenberger et al. ${ }^{35}$ which showed that the worker role was instrumental in developing self-worth. All participants felt that they became competent in their work skills with time and that this resulted in role development and provided opportunities for professional growth, recognition and promotion. Participants also added that the worker role provided opportunities to transfer these skills into their home environments, which was instrumental in developing self-worth.

Varying degrees of physical, cognitive, psychosocial and work specific impairments due to a severe TBI resulted in reduced participation in the worker role. For participants who returned to work, their confidence in work participation had reduced. For participants who did not return to work, they were uncertain about how they could participate in work tasks in the future. This poor confidence, uncertainty and disbelief-in-self resulted in reduced self-worth. As a result, participants further isolated themselves and the loss-of-self became worse. This finding was in keeping with literature, suggesting that a loss-of-self and identity is an inherent consequence of $\mathrm{TBI}^{5,6,8,36}$.

Vocational rehabilitation intervention facilitated self-worth. Only two of the eleven participants participated in vocational rehabilitation prior to the study. This allowed them to engage in work tasks within the confinements of their residual abilities and facilitated elements of recovery. The significance of this recovery was expressed by one participant as being ... exponential, because the dedication of the rehab team was out of this world [M8]. The nine participants who did not have vocational rehabilitation intervention reported more uncertainty, less confidence in their abilities and reduced self-belief. This finding is in keeping with literature that vocational rehabilitation intervention improves self-efficacy ${ }^{37}$.

Participants attributed emotional investments in the worker role to the need to make a difference and serve the community. This developed self-worth, self-esteem and positive emotions and behaviours. A consequence of severe TBI is emotional and behavioural volatility. All participants reported having depression which impeded their motivation to participate in the worker role. Feelings of reduced confidence and disbelief-in-self were compounded. This resulted in isolation and poor motivation to serve the community and perpetuated the cycle of depression. Participants also reported an inability to manage their aggression or temper. As a result, support from friends, family, colleagues and employers waned and return to and maintaining pre-injury employment was further disadvantaged. These findings support emotional and behavioural dyscontrol, a term described by Arciniegas and Wortzel ${ }^{38}$ as a disabling consequence of TBI.

The second major theme to emerge from this study was 'support'. Participants described this support as comprising personal support from friends and family, work support from colleagues and employers and rehabilitative support following vocational rehabilitation intervention. Support is accepted as a fundamental factor that either facilitates or impedes the return-to-work of people with TBI's ${ }^{18,39}$. The degree to which support was highlighted in the study upholds this view. When support was given by friends and family, participants did not feel pressurised to return-to-work, regardless of age. This provided them with time to concentrate on their recovery process. When they did return to work, motivational support from colleagues and employers offered these participants a sense of confidence to engage holistically in the worker role despite their difficulties. This helped them develop a sense of acceptance of their injury. Through vocational rehabilitation, a deeper level of understanding between the individual, family and employer was facilitated. The support participants received paved the way for reasonable accommodation. As a result, their competencies in their established skills were re-enhanced. This promoted confidence and self-belief to fulfil the worker role.

As a direct opposite to the facilitators arising from support were the barriers as a result of the lack of support. Family and employers who had less confidence in the participants' abilities to fulfil the worker role was viewed as poor personal and work support. This resulted in participants feeling uncertain about the progression of their recovery and ability to participate in their work environment which led to further isolation. 
The findings of the research study therefore gave some insights into personal and environmental factors which enhanced or impeded participants return-to-work following their injury.

\section{IMPLICATIONS OF THE RESEARCH}

Inferences from the research suggest that the value of return-towork is a facilitator for self-worth in individuals with severe TBI. This study further suggests that participation in work is a precursor to participation in other areas of daily living and return-to-work should not be a neglected aspect of the rehabilitation process. By exploring vocational rehabilitation with participants who had not received this intervention, they were unaware of what this type of rehabilitation is. This indicates a reduced awareness of vocational rehabilitation within the South African context and indicates that not all individuals having sustained a TBI have access to return-to-work interventions. This supports the notion that vocational rehabilitation is isolated and superficial ${ }^{8,26,27}$. It is envisioned that the implementation of vocational rehabilitation at a Primary Healthcare level could address the problem of accessibility and facilitate return-to-work for individuals with severe TBI. By taking into consideration a solid skills-base and a stable and secure work environment, this study highlights the need for vocational rehabilitation to consider preinjury skills and environments to facilitate and accelerate returnto-work. Finally, the identification of both internal (motivation) and external (societal perceptions) factors could guide the development of a holistic, client-centred approach to vocational rehabilitation strategies and programmes for severe TBls.

\section{LIMITATIONS OF THE STUDY}

While the first author was aware of her role and how her interpretations may have influenced the research process, the interview process was done singularly, which may have influenced the data obtained. However, interpretation of the data was done together with peers in an attempt to control this. As the research used a qualitative design to answer the research aim, it cannot be generalised to the population at large. There were only two female participants which implies that the findings in this study were biased towards the male opinions. One participant was not proficient in English and thus a translator was required. The problem in finding a translator for this participant may have resulted in some information being misconstrued. It is further acknowledged that only two participants received vocational rehabilitation and while the information was a pertinent facilitating factor in the return-to-work, it was not sufficient to develop this theme further.

\section{CONCLUSION}

In this study, factors that influenced the return-to-work for severe TBl's who were employed in a stable, secure environment for more than three years prior to the injury, were identified and explored. The findings in this study indicated that both the internal and external factors played a critical role in the return-to-work for individuals with severe TBI's. The results further indicated that participation in work was important in developing self-worth for participation in other areas of daily living. Results also indicated that rehabilitation and support was vital in maintaining self-worth after an injury and could be enhanced through vocational rehabilitation. Overall, the results showed that the return-to-work success for individuals with severe TBI was dependent on rehabilitation, personal factors and work support.

\section{REFERENCES}

I. Teasdale G, Maas A, Lecky F, Manley G, Stocchetti N, Murray G. The Glasgow Coma Scale at 40 years: standing the test of time. The Lancet Neurology. 20 I4; 13(8): 844-54.

2. van Velzen JM, van Bennekom CA, Edelaar MJ, Sluiter JK, FringsDresen $\mathrm{MH}$. How many people return to work after acquired brain injury? A systematic review. Brain Injury. 2009; 23(6): 473-88.

3. Conklin J, Flaumer CP, Venables, T. "Traumatic Brain Injury (TBI): Transformed By Injury, Occupational Therapy's Role in Return to work following a TBI" (20I5) Collaborative Research and Evidence shared Among Therapists and Educators (CREATE day). Paper 29. $<$ http://jdc.jefferson.edu/createday/29 > (18 August 2016).

4. Gilworth G, Eyres S, Carey A, Bhakta BB, Tennant A. Working with a brain injury: personal experiences of returning to work following a mild or moderate brain injury. Journal of Rehabilitation Medicine. 2008; 40(5): 334-9.

5. Hooson JM, Coetzer R, Stew G, Moore A. Patients' experience of return to work rehabilitation following traumatic brain injury: a phenomenological study. Neuropsychological Rehabilitation. 2013; 23(I): 19-44.

6. Bush EJ, Hux K, Guetterman TC, McKelvey M. The diverse vocational experiences of five individuals returning to work after severe brain injury: A qualitative inquiry. Brain Injury. 2016; 30(4): I-I5.

7. Lundqvist A, Samuelsson K. Return to work after acquired brain injury: a patient perspective. Brain Injury. 20 I 2; 26 (I3- I4): I574-85.

8. Soeker MS, Van Rensburg V, Travill A. Individuals with traumatic brain injuries perceptions and experiences of returning to work in South Africa. Work. 20I2; 42(4): 589-600.

9. Basso A, Previgliano I, Servadei F. Traumatic brain injuries. In:World Health Organisation, editors. Neurological disorders: Public Health Challenges. Switzerland WHO Press 2006.

10. World Head Injury Awareness Day. National Institute for Occupational Health. Topical Issues. 2016. Available from: http://www.nioh. ac.za/?page $=$ topical\&id $=13 \&$ rid $=56$.

II. Bruns J, Hauser WA. The Epidemiology of Traumatic Brain Injury: A Review. Epilepsia. 2003; 44(s I0): 2-10.

12. Statistics South Africa. Mortality and causes of death, 2014. [serial online]. c2015 [cited 2016 Oct 24]; Pretoria. Available from http:// www.statssa.gov.za.

13. Joseph SS. Bokop C. Nqoloba Dr. Mabovula Dr. Muballe Prof. Imputo Prof. Epidemiology of patintes presenting with traumatic brain injury at the Nelson Mandela Academic Hospital. Lecture presented at the Neurosurgery Congress of South Africa; 2016 Walter Sisulu University Mthatha, Eastern Cape; Available from http://www.snsacongress.co.za/.

14. Lewis C. Wood D. Interpersonal Violence as a major contributor towards the skewed burden of trauma in KwaZulu-Natal, South Africa. South African Medical Journal. 2015; 105(I0): 827-30.

15. Dube AK. The role and effectiveness of disability legislation in South Africa [unpublished research. Stanley E. editor. Samaita Consultancy and Programme Design; 2005.

16. Andelic N, Stevens LF, Sigurdardottir S, Arango-Lasprilla JC, Roe C. Associations between disability and employment I year after traumatic brain injury in a working age population. Brain Injury. 20I2; 26(3): 26I-9.

17. Autret K, Zouker J, Albanese J-B, Berthier T, Durufle A, Le Meur $C$, et al. Return to work after brain injury: A retrospective study of 85 patients followed by an occupational reintegration unit. Annals of physical and rehabilitation medicine. 2015; 58(5): 308-II.

18. Forslund MV, Roe C, Arango-Lasprilla JC, Sigurdardottir S, Andelic $\mathrm{N}$. Impact of personal and environmental factors on employment outcome two years after moderate-to-severe traumatic brain injury. Journal of rehabilitation medicine. 2013; 45(8): 80I-7.

19. Watt N. Penn C. Predictors and Indicators of Return to Work Following Traumatic Brain Injury in South Africa: Findings from a Preliminary Experimental Database. South African Journal of Psychology. 2000; 30(2): 27-37.

20. Grauwmeijer E, Heijenbrok-Kal MH, Haitsma IK, Ribbers GM. A prospective study on employment outcome 3 years after moderate to severe traumatic brain injury. Archives of physical medicine and rehabilitation. 2012; 93(6): 993-9.

21. Richardson $\mathrm{C}$. Factors influencing self-awareness following traumatic brain injury. Journal of Head Trauma Rehabilitation. 20I5;30(2):43.

22. Kelley E. Self-awareness and neurobehavioral outcomes, 5 years or more after moderate to severe brain injury. Journal of Head Trauma Rehabilitation. 2014; 29(2): 147.

23. Sasse N. Self-awareness and health-related quality of life after traumatic brain injury. Journal of Head Trauma Rehabilitation. 2013; 28(6): 464. 
24. Waddell G, Burton AK, Kendall NAS. Vocational rehabilitation - what works, for whom, and when? London: TSO; 2008: 360.

25. National Rehabilitation Policy. In: Health Do, editor. Republic of South Africa Ministry of Health; Republic of South Africa; 2000.

26. Coetzee Z, Goliath C, van der Westhuizen R, Van Niekerk L. Reconceptualising vocational rehabilitation services towards an intersectoral model. South African Journal of Occupational Therapy. 20II; 4I: 32-7.

27. Uys LR, Phillips N, Zulu RN. Vocational rehabilitation in rural South Africa. Psychiatric Rehabilitation Journal. 1997; 2I(I): 3 I-9.

28. Larsson J, Holmstrom I. Phenomenographic or phenomenological analysis:does it matter? Examples from a study on anaesthesiologists' work. International Journal of Qualitative Studies on Heath and Well-being. 2007; 2(I): 55-64.

29. Stenfors-Hayes T, Hult H, Dahlgren MA. A phenomenographic approach to research in medical education. Medical Education. 2013; 47: $261-270$.

30. Biernacki SD. Reliability of the worker role interview. The American journal of occupational therapy. 1993; 47(9): 797-803.

31. Marton F. Phenomonography - Describing conceptions of the world around us. Instructional Science. 198I; 10: 177-200.

32. Braun V, Clarke V. Using thematic analysis in psychology. Qualitative Research in Psychology. 2006; 3(2): 77-I0I.

33. Ornek F. An overview of a theoretical framework of phenomenography in qualitative education research: An example from physics education research. Asia-pacific Forum on Science Learning and Teaching.2008; 9(2): I-I4.

34. Anney VN. Ensuring the quality of the findings of qualitative research: looking at Trustworthiness Criteria. Journal of Emerging Trends in Educational Research and Policy Studies 20I4; 5(2): 272-28I.

35. Greenberger E, O'Neil R. Spouse, Parent, Worker: Role Commitments and Role-Related Experiences in the Construction of Adults' Well-Being. Developmental Psychology. 1993; 29(2): I8I-97.

36. Nochi M. "Loss of self" in the narratives of people with traumatic brain injuries: A qualitative analysis. Social Science \& Medicine. 1998; 46(7): 869-78.

37. Bjorkdahl A. The return to work after a neuropsychological programme and prognostic factors for success. Brain Injury. 20 I0; 24(9): |06I-9.

38. Arciniegas DB, Wortzel HS. Emotional and behavioral dyscontrol after traumatic brain injury. Psychiatric Clinics of North America. 20I4; 37(I): 3I-53.

39. Bonneterre V, Pérennou D, Trovatello V, Mignot N, Segal P, Balducci $F$, et al. Interest of workplace support for returning to work after a traumatic brain injury: A retrospective study. Annals of physical and rehabilitation medicine. 2013; 56(9-10): 652-62. 